УДК 330

\title{
ВЛИЯНИЕ ПАНДЕМИИ КОРОНАВИРУСНОЙ ИНФЕКЦИИ COVID-19 НА СОСТОЯНИЕ МИРОВОЙ ЭКОНОМИКИ
}

\author{
Батукаева Анжела Руслановна \\ старший преподаватель \\ Шовхалова Зайдат Салмановна
}

ФГБОУ ВО «Чеченский государственный университет»

\begin{abstract}
Аннотация: В статье освещается актуальная на сегодняшний день проблема - пандемия коронавирусной инфекции covid-19, а также влияние, которое она оказала на состояние мировой экономики. В центре исследования динамика экономической системы и изменения, которые она претерпела в последствии введенных ограничительных мер и самоизоляции. В процессе работы изучена актуальная статистика и официальные данные, которые позволили составить наиболее полный портрет текущего состояния мировой экономики.
\end{abstract}

Ключевые слова: Пандемия, экономическая система, COVID-19, экономика, мировая экономика, экономический рост.

\section{IMPACT OF THE COVID-19 CORONAVIRUS PANDEMIC ON THE GLOBAL ECONOMY}

\section{Batukaeva Angela Ruslanovna Shovhalova Zaydat Salmanovna}

\begin{abstract}
The article highlights the current problem-the covid-19 coronavirus pandemic, as well as the impact it has had on the state of the world economy. The research focuses on the dynamics of the economic system and the changes it has undergone as a result of the imposed restrictive measures and self-isolation. In the course of the work, we studied current statistics and official data, which allowed us to create the most complete portrait of the current state of the world economy.

Key words: Pandemic, economic system, COVID-19, economy, world economy, economic growth.
\end{abstract}




\section{МОЛОДЕЖНАЯ НАУКА КАК ФАКТОР И РЕСУРС ИННОВАЦИОННОГО РАЗВИТИЯ}

Национальные хозяйства, объединённые различными видами связей, образуют мировую экономику, которая представляет собой многоуровневую и глобальную систему.

На сегодняшний день непосредственное влияние на состояние мировой экономики оказывает появление такой проблемы как пандемия коронавирусной инфекции covid-19 (острая респираторная инфекция, представляющая собой опасное заболевание).

В связи с массовыми заболеваниями по всему миру Всемирная организация здравоохранения официально объявила о чрезвычайной ситуации международного уровня.

За исключением стремительного распространения болезни и введения ограничительных мер (самоизоляция, карантин) пандемия COVID-19 имеет существенные последствия как для социальной составляющей стран, так и для экономической. Средства массовой информации все чаще обозначают воздействие вируса на общественную жизнь термином «коронакризис», и это слово максимально точно иллюстрирует нынешнее положение дел.

Мировая экономика в связи с ограничительными мерами, введенными для борьбы с пандемией пережила в 2020 году глубокий спад. Промышленный сектор вынес удар, какого не было со времен глобального финансового кризиса. Большая часть экономических институтов значительно понизила прогнозы экономического роста по всему миру. Сокращение производственной активности, сокращение сектора услуг, снижение цен на энергоносители больно ударила по экономике Китая, затем Италии, России и т. д. С весны наблюдается резкое снижение доходности облигаций и цен на акции на крупнейших рынках мира. Один из крупнейших секторов экономики - туризм, оказался наиболее уязвимым перед пандемией. Воздействие туристической отрасли будет еще больше тормозить рост сферы услуг, таких как общественное питание, розничная торговля и проживание. Миллионы людей остались без возможности работать, уровень безработица на пару с инфляцией существенно возрос. Сотни частных предприятий приостановили свою деятельность. Занятость населения - очень важная составляющая экономического развития, она гарант стабильности и постоянного роста.

По данным Росстата, уровень безработицы в России к осени стал равен $6 \%$ [4]. Стоит отметить, что официально в центрах занятости зарегистрировано около 3 миллион граждан, а реальное число безработных достигло 4,6 миллион. Европейский рынок труда за время пандемии потерял около 5,5 млн рабочих 
мест, что равно 2,6\% от их общего количества. Для борьбы с растущей безработицей и приостановлением деятельности многих предприятий большинство стран, такие как Франция, Италия, Германия воспользовались возможность разработать и реализовать программу государственной поддержки.

Это поможет замедлить на время рост безработицы, однако остановить этот процесс также невозможно. В США уровень безработицы достиг 14,7\%. Около 20 миллионов людей потеряли работу за пару недель и это один из самых худших показателей за всю историю США.

Эпидемия обозначила взаимосвязь денежных потоков и их функционирование в определенной системе. На текущий период эта связь нарушена. Снижение доходов привело к снижению потребления, нанося огромный урон хозяйствующим субъектам. Государственные расходы значительно возросли в борьбе со сложившейся ситуацией.

Показатели торговли подтверждают динамику снижения. К весне 2020 года индекс торгового барометра Всемирной торговой организации (ВТО) составил 95,5, (снизился на 1,1, относительно предыдущего периода). ВТО обозначила, что глобальные события в области здравоохранения и торговые трения между некоторыми странами станут причиной стремительного снижения темпов роста мировой торговли.

Внутренний валовый продукт (ВВП) [1, с. 125] большинства стран мира показал существенно сниженные показатели к началу первой половины 2020 , суммарный ВВП стран G20 упал на $3.4 \%$, а стран ЕС - на $11.9 \%$ [3].

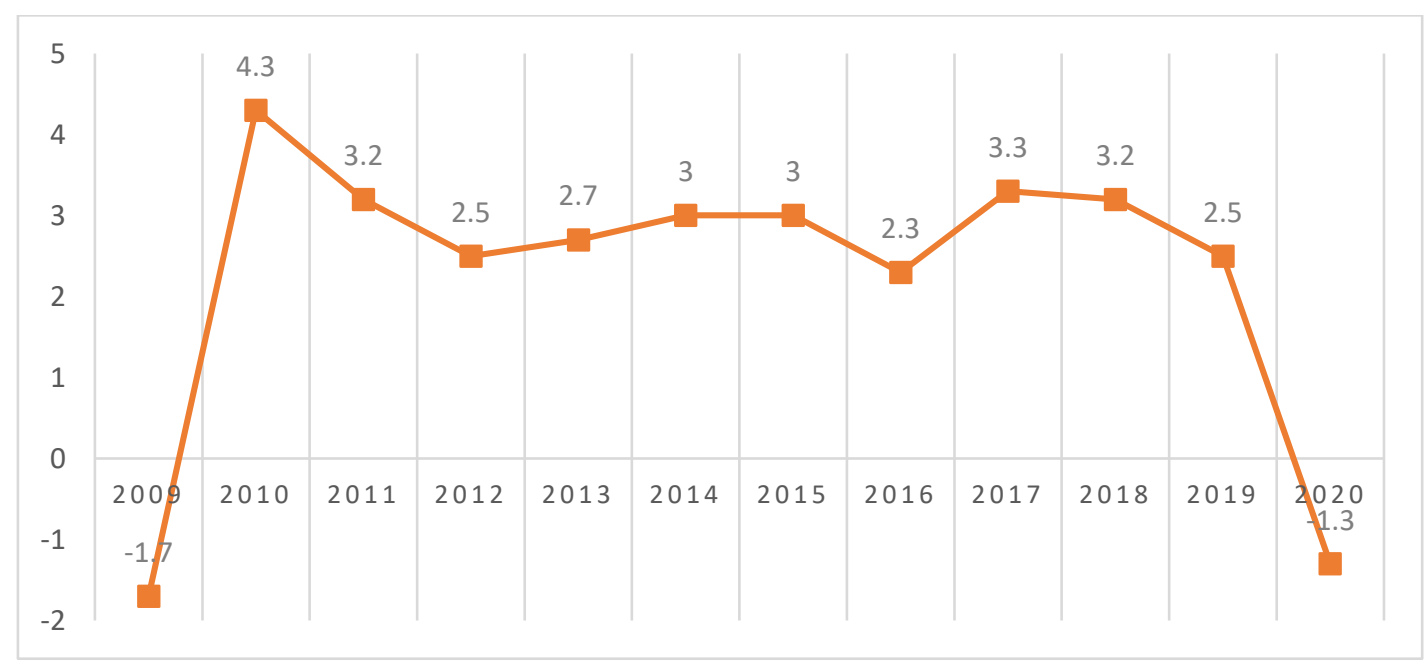

Рис. 1. Динамика мирового ВВП, в \% 


\section{МОЛОДЕЖНАЯ НАУКА КАК ФАКТОР И РЕСУРС ИННОВАЦИОННОГО РАЗВИТИЯ}

В 2009 году мировой ВВП опустился ниже нуля, однако с 2010 до 2019 года экономический рост на глобальном уровне отличался стабильностью и положительной динамикой. Несмотря на хорошие темпы роста в течении последнего десятилетия, в связи с пандемией мировой показатель ВВП вновь опустился ниже нуля (рис.1).

С января по май 2020 общий экспорт из России упал на $22 \%$ относительно аналогичного периода 2019 года, составив 135 млрд. долларов. Однако основное падение стоимостных показателей обеспечили нефть и топливо. Без них понижение составило всего 1,1\%. С точки зрения цен на сырьевые товары международные цены на сырьевые товары в целом упали. Снизились цены на энергоносители, так в феврале мировые цены на энергоносители упали на 12,7 \% в месячном исчислении. Среди них сырье снизилось на 1,4 \%, а металлы и минералы упали на 6,0 \%. Стоит отметить, значительное снижение цен на нефть и нефтепродукты. Причиной стали такие факторы, как глобальное распространение эпидемии и неспособность достичь соглашения о сокращении добычи на совещании организации стран экспортеров нефти (ОПЕК). Весной средняя цена пакета сырой нефти ОПЕК упала на 28,2 \% до 34,71 долл. США за баррель. Такого упадка не было с 2016 года.

На текущий период международные организации снова объявили о снижении ожиданий от годовых показателей роста мировой экономики, так как негативные последствия коронавирусной инфекции продолжают оказывать давление на все государства и их благосостояние. Организация экономического сотрудничества и развития (ОЭСР) предполагает, что мировая экономика будет иметь отрицательный рост в начале 2020 года, и корректирует годовой прогноз темпов роста с 2,9 \% до 2,4 \%. Президент Международного валютного фонда (МВФ) заявила, что темпы роста мировой экономики в 2020 году будут ниже 2,9 \%, как это было в 2019 году. Международная финансовая ассоциация (IIF) опубликовала доклад, в котором говорится, что показатели в этом году могут быть близки к $1 \%$, а это в сравнении с прошлым годом намного ниже.

Более 40 стран в срочном порядке и в одно и то же время ввели карантинные меры, что сильно ударило по мировой экономике. Существенные потери понес сектор малого и среднего бизнеса, туристические агентства, общественные транспорт, ресторанный бизнес, сфера сервиса, индустрия развлечений, сектор промышленного производства. 
Однако с появлением коронавирусной инфекции наблюдается рост цифровизации экономики, сегодня интернет и сети своего рода являются главным средством к существованию как людей, так и бизнесов. Возможно, переход предприятий и даже целой экономической отрасли на новые модели бизнес-процессов, основанных на информационных технологиях, станут выходом из «коронакризиса».

Многие эксперты и аналитики смотрят на рынок позитивно и предполагают, что кризисная ситуация на мировом рынке продлится недолго, после чего акции быстро восстановятся и смогут достигнуть новых максимумов. Несмотря на все оптимистичные прогнозы, прийти к стабильному мировому развитию после такого удара будет совсем нелегко, однако при правильной государственной политике и соблюдении всех мер общей безопасности преодолеть данный этап и постепенно вернуться к стабильности будет более чем возможно.

\section{Список литературы}

1. Хасбулатов Р.И. Мировая экономика в 2 ч. Часть 1. Учебник для вузов 2-е изд., перераб. и доп. - Москва: Издательство Юрайт, 2019. - 689 с.

2. Хасбулатов Р.И. Мировая экономика в 2 ч. Часть 2. Учебник для вузов 2-е изд., перераб. и доп. - Москва: Издательство Юрайт, 2019. - 691 с.

3. Аналитические материалы http://www.coface.ru/Novosti-i-Publikacii/ Publikacii/Vliyanie-COVID-19-na-ekonomiku.-Analiticheskie-materialy-Coface (дата обращения 27.11.2020 г.)

4. Федеральная служба государственной статистики https://rosstat.gov.ru/ (дата обращения 27.11.2020 г.)

(C) 3.С. Шовхалова, А.Р. Батукаева, 2020 